\title{
Individual courses and determinants of fear of cancer recurrence in long-term breast cancer survivors with and without recurrence
}

\author{
Paula Heidkamp ${ }^{1,2}$ (1) Clara Breidenbach ${ }^{3} \cdot$ Kati Hiltrop $^{1,2} \cdot$ Christoph Kowalski $^{3} \cdot$ Anna Enders $^{4} \cdot$ Holger Pfaff $^{5}$. \\ Birgitta Weltermann ${ }^{6} \cdot$ Franziska Geiser $^{2,7} \cdot$ Nicole Ernstmann $^{1,2}$
}

Received: 30 December 2020 / Accepted: 30 May 2021 / Published online: 17 June 2021

(c) The Author(s) 2021

\begin{abstract}
Objective This study investigated the prevalence, individual courses, and determinants of fear of cancer recurrence (FoR) in long-term breast cancer survivors (BCSs) with and without recurrence.

Methods A total of 184 breast cancer survivors were surveyed at four measurement time points: during hospitalization (T1), 10 weeks (T2), 40 weeks (T3), and 5-6 years (T4) after hospital discharge. Descriptive statistics, chi-square tests, and logistic regression were performed.

Results Respondents were females and 57 years old, on average. At T1, T3, and T4, 54.8\%, 31.6\%, and 29.7\% of BCSs, respectively, were classified as having dysfunctional levels of FoR. Dysfunctional FoR decreased from T1 to T3 $\left(\chi^{2}(1)=17.11, p=0.000 ; \mathrm{N}=163\right)$ and remained stable afterwards. Eight subgroups of individual courses of FoR over time could be described: (1) constant functional FoR; (2) constant dysfunctional FoR; (3) improving from dysfunctional to functional FoR from T1 to T3; (4) improving from dysfunctional to functional FoR from T3 to T4; (5) worsening from functional to dysfunctional FoR from T1 to T3; (6) worsening from functional to dysfunctional FoR from T3 to T4; (7) dysfunctional FoR at T1 and T4, and functional FoR in between; and (8) functional FoR at T1 and T4, and dysfunctional FoR in between. Logistic regression analysis revealed that being divorced/widowed, showing high levels of fatigue, being treated by chemotherapy, and having low confidence in treatment were associated with dysfunctional FoR 5 to 6 years after diagnosis (Nagelkerkes' Pseudo-R2 =0.648).

Conclusions The findings reveal that FoR is a significant issue in long-term BCSs and has the potential to become a persistent psychological strain. We emphasize the need for increased awareness of FoR among BCSs and the need for support programs.
\end{abstract}

Keywords Anxiety $\cdot$ Breast cancer $\cdot$ Fear of cancer recurrence $\cdot$ Oncology $\cdot$ Relapse $\cdot$ Survivorship

Paula Heidkamp

paula.heidkamp@ukbonn.de

1 Center for Health Communication and Health Services Research (CHSR), Department for Psychosomatic Medicine and Psychotherapy, University Hospital Bonn, Bonn, Germany

2 Center for Integrated Oncology Bonn (CIO), University Hospital Bonn, Bonn, Germany

3 German Cancer Society, Berlin, Germany

4 Federal Centre for Health Education, Cologne, Germany

5 Institute for Medical Sociology, Health Services Research and Rehabilitation Science (IMVR), University of Cologne, Cologne, Germany

6 Institute of General Practice and Family Medicine, University of Bonn, Bonn, Germany

7 Department of Psychosomatic Medicine and Psychotherapy, University Hospital Bonn, Bonn, Germany

\section{Background}

Even years after diagnosis and active treatment, cancer survivors suffer from their disease in multiple ways and report lower levels of quality of life compared to the non-affected population $[1,2]$. A widespread source of psychological distress, which is not only one of the most important strains in cancer patients in acute treatment [3], but also affects long-term cancer survivors, is the fear of cancer recurrence (FoR) [4, 5]. FoR is defined as "Fear, worry, or concern relating to the possibility that cancer will come back or progress." [6] FoR is basically described as an appropriate reaction to cancer and its life-threatening potential and can enhance motivation, for example, to keep appointments for follow-up care or to engage in a healthy lifestyle [7]. However, FoR can also become dysfunctional 
when clinically significant severity is reached [6-8] and can be associated with lower quality of life, depression, and anxiety, even years after diagnosis $[9,10]$. There is an expert consensus that dysfunctional FoR comprises certain characteristics, such as high levels of preoccupation and worry, which are persistent, as well as hypervigilance to bodily symptoms $[6,8]$. In addition, high levels of FoR are associated with a higher risk of diagnosis with a psychiatric disorder compared to non-clinical levels [11]. Even years after diagnosis, a substantial number of cancer survivors suffer from FoR, which can be classified as dysfunctional [9-11]. However, studies that use predefined cutoff values for the clinical significance of FoR are rare; therefore, interpretations in terms of functional or dysfunctional levels of FoR in cancer survivors are limited $[4,5]$. Regarding the course of FoR in cancer survivors over time, most studies found FoR to be stable $[4,5]$. However, for a better understanding of FoR in long-term cancer survivors, not only mean values but also more individual courses of FoR need to be considered. The first studies that investigated group-based trajectories of FoR in cancer patients identified three patterns: constant low FoR over time, constant high FoR over time, and decreasing FoR over time [12, 13]. As these studies focused on the first year of the cancer, generalization to long-term cancer survivors is limited. Furthermore, for a better understanding of individual experiences of FoR in the long term, it should be considered whether breast cancer survivors (BCSs) actually have a recurrence over the course of the disease or not. Previous studies found both positive associations between having a recurrence and FoR and no significant relationship between these variables $[5,9]$.

Therefore, the present study aims to (1) investigate the prevalence of functional and dysfunctional FoR in longterm BCSs over a period of 5 to 6 years after diagnosis, (2) describe individual courses of functional and dysfunctional levels of FoR of BCSs with and without recurrence from hospitalization to 5-6 years after diagnosis, and (3) analyze the association of dysfunctional FoR in long-term BCSs 5-6 years after diagnosis with sociodemographic and health- and treatment-related variables.

\section{Methods}

\section{Study design and participants}

The B-CARE project ("breast cancer patients' return to work") was initiated in 2018 to study sociodemographic and psychosocial determinants of breast cancer patients' use of medical rehabilitation and return to work. B-CARE is a longitudinal study that uses survey data of breast cancer patients from four measurement time points: during hospitalization (T1), 10 weeks after hospital discharge (T2), 40 weeks after hospital discharge (T3), and 5-6 years after hospital discharge (T4) (T1: $\mathrm{n}=1359 ; \mathrm{T} 2: \mathrm{n}=1248 ; \mathrm{T} 3: \mathrm{n}=1202$; T4: $\mathrm{n}=184$ ). The flow of participants is shown in Fig. 1. Data from the first three measurement time points were collected during the preceding PIAT project ("Strengthening patient competence: Breast cancer patients' information and training
Fig. 1 Flow of participants. Note: The number of respondents composes of participants who consecutively participated in every survey wave and those who participated at least once. Dropouts occurred due to nonresponse, death, or unverifiable addresses

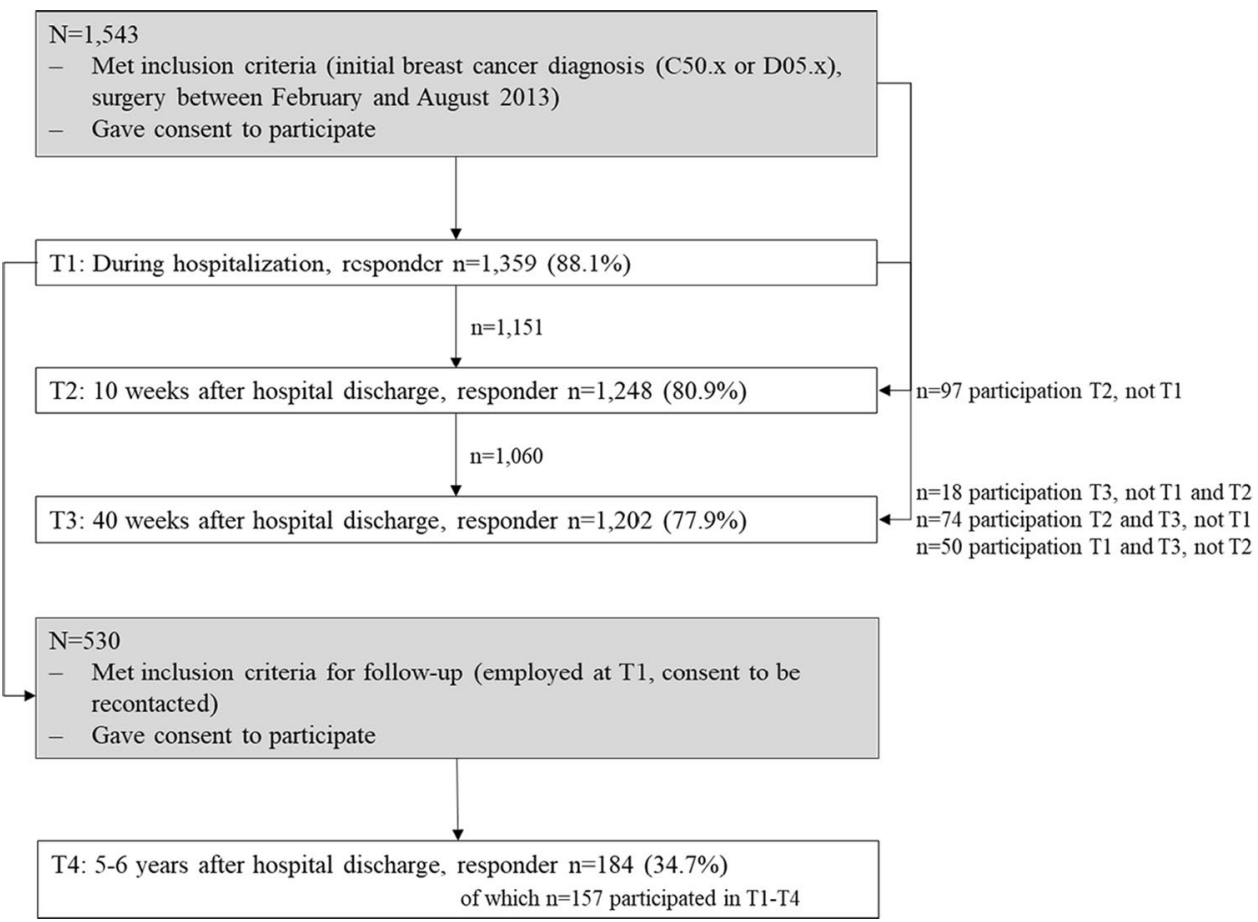


needs"). The PIAT study was initiated in 2013 and patients with an initial diagnosis of breast cancer $(n=1359$; C50.x or D05.x) from $n=60$ breast cancer centers throughout Germany were recruited for the study $[14,15]$. Patients were surveyed during hospitalization. They received a questionnaire via mail 10 weeks and 40 weeks after hospital discharge. In 2019, B-CARE carried out a follow-up survey of a subsample of 530 patients who gave their consent to be re-contacted and who were working at the time of their diagnosis. Hundred and eighty-four patients participated in the survey 5 to 6 years after hospital discharge (response rate $=35 \%$ ). Responder and non-responder at $\mathrm{T} 4$ did not differ significantly regarding FoR, medical, psychosocial, and sociodemographic characteristics (e.g., UICC TNM stage, number of comorbidities, age) (analyses not shown). Detailed information on the study design and sampling process can be found elsewhere [16].

\section{Measurements}

\section{Fear of cancer recurrence}

The short form of the Fear of Progression Questionnaire (FoP-Q-SF) [17] was used to collect data at T1, T3, and T4. The FoP-Q-SF consists of 12 items and includes four subscales (affective reactions, partnership/family, occupation, and loss of autonomy) of the original version [18]. Table 1 gives an overview of the items of the FoP-Q-SF [19]. The 12 items were assessed using a 5-point Likert scale ( $1=$ "never" to $5=$ "very often"), leading to total scores ranging from 12 to 60, where higher values indicate higher levels of FoR. A cutoff score of 34 or above was used to identify dysfunctional levels of FoR [20]. At T3, item 12 of the FoP-Q-SF was missing in the survey, leading to a total of 11 items. In order to ensure that the results (possible range: 11-54) were still comparable to the results of the original 12-item version, the total scores were standardized to the original metric (possible range: 12-60). Therefore, total scores of
Table 2 Variables measured at T1, T2, T3, and T4

\begin{tabular}{|c|c|c|c|c|}
\hline Variables & $\mathrm{T} 1$ & $\mathrm{~T} 2$ & $\mathrm{~T} 3$ & $\mathrm{~T} 4$ \\
\hline Fear of cancer recurrence (FoP-Q-SF) & $\mathrm{x}$ & & $\mathrm{x}$ & $\mathbf{x}$ \\
\hline \multicolumn{5}{|l|}{ Sociodemographic variables } \\
\hline Age & & & & $\mathbf{x}$ \\
\hline Family status & $\mathrm{x}$ & $\mathrm{x}$ & $\mathrm{x}$ & $\mathbf{x}$ \\
\hline Number of children & & & & $\mathbf{x}$ \\
\hline Employment status & $\mathrm{x}$ & $\mathrm{x}$ & $\mathrm{x}$ & $\mathbf{x}$ \\
\hline Vocational education level & $\mathbf{x}$ & & & \\
\hline \multicolumn{5}{|l|}{ Health-related variables } \\
\hline Cancer classification (UICC) & $\mathbf{x}$ & & & \\
\hline Number of comorbidities & $\mathrm{x}$ & & & $\mathbf{x}$ \\
\hline Recurrence status & & & & $\mathbf{x}$ \\
\hline Fatigue (Fatigue Assessment Questionnaire) & & & & $\mathbf{x}$ \\
\hline \multicolumn{5}{|l|}{ Treatment-related variables } \\
\hline Chemotherapy & $\mathbf{x}$ & $\mathbf{x}$ & $\mathbf{x}$ & \\
\hline Radiation therapy & $\mathbf{x}$ & $\mathbf{x}$ & $\mathbf{x}$ & \\
\hline Hormonotherapy & $\mathbf{x}$ & $\mathbf{x}$ & $\mathbf{x}$ & \\
\hline Confidence in treatment & $\mathbf{x}$ & & & \\
\hline
\end{tabular}

Note: Variables examined in the logistic regression analysis in bold

the 11 items were divided by their possible maximum values based on the respective number of missing values for each participant. Values were then multiplied by the maximum possible value of the original instrument.

\section{Determinants of FoR}

To identify the determinants of functional and dysfunctional FoR at T4, data on sociodemographic and health- and treatment-related variables were collected. Table 2 gives an overview of the variables measured at T1, T2, T3, and T4. Sociodemographic data, such as age and number of children, were assessed in the questionnaire at T4. The variables family status and employment status were assessed at T1, T2, T3, and $\mathrm{T} 4$. In order to analyze the most current data on family
Table 1 Items of the short form of the Fear of Progression Questionnaire (FoP-Q-SF)
(1) Being afraid of disease progression

(2) Being nervous prior to doctor's appointment or periodic examinations

(3) Being afraid of pain

(4) Being afraid of becoming less productive at work

(5) Having physical sensations, e.g., rapid heartbeat, stomach ache, nervousness

(6) Being afraid of the possibility that the children could contract cancer

(7) Being afraid of relying on strangers for activities of daily living

(8) Being afraid of no longer be able to pursue hobbies

(9) Being afraid of severe medical treatments in the course of the illness

(10) Worrying that medication could damage the body

(11) Worrying about what will become of the family

12) Being afraid of not being able to work anymore 
status and employment status, these variables were only examined at T4. The variable "highest vocational education level achieved" was assessed at T1. Data on cancer classification were added by the clinical personnel at $\mathrm{T} 1$, according to the categories of the Union Internationale Contre le Cancer (UICC) [21]. The number of comorbidities was assessed at $\mathrm{T} 1$ and T4. In order to use the most current data on comorbidities, the variable was only examined at $\mathrm{T} 4$. Recurrence status was assessed using the questionnaires at T4. To collect data on fatigue, the Fatigue Assessment Questionnaire [22] was used at T4. The FAQ consists of 20 items and three subscales (physical, affective, and cognitive fatigue). Treatment-related characteristics, such as being treated by chemotherapy, radiation therapy, or hormonotherapy, were assessed in the questionnaire at $\mathrm{T} 1, \mathrm{~T} 2$, and $\mathrm{T} 3$. If a treatment type was provided at least once over the three measurement time points, it was considered given. The single item variable "confidence in treatment," which measures a positive belief in the outcome of the treatment, was assessed in the questionnaire at $\mathrm{T} 1 \mathrm{using}$ a 10 -point Likert scale $(0=$ "not confident", $10=$ "confident"). The 20 items were assessed using a four-point Likert scale ( $0=$ "not at all" to $3=$ "very much"), leading to the highest possible sum score of 60 , where higher values indicate higher levels of fatigue.

\section{Statistical methods}

Statistical analyses were conducted using IBM SPSS Statistics version 24. Missing values were deleted list wise. To describe the prevalence of functional and dysfunctional levels of FoR over time, descriptive statistics and chi-square tests were conducted.

Individual courses of FoR were described for each participant with data on FoR available at T1, T3, and T4. Furthermore, individual courses of FoR were illustrated separately for participants with and without recurrence. By using the cutoff of 34, the participants were classified as having either functional or dysfunctional levels of FoR at T1, T3, and T4. Based on theoretical assumptions regarding the number of possible courses ( 3 time points, 2 values), eight different groups of courses were expected: (1) functional FoR at T1, T3, and T4; (2) dysfunctional FoR at T1, T3, and T4; (3) functional FoR at T1 and T3, and dysfunctional FoR at T4; (4) functional FoR at T1 and dysfunctional FoR at T3, and T4; (5) dysfunctional FoR at T1 and T3, and functional FoR at T4; (6) dysfunctional FoR at T1 and functional FoR at T3, and T4; (7) functional FoR at T1 and T4, and dysfunctional FoR at T3; (8) dysfunctional FoR at T1 and T4, and functional FoR at T3. Depending on the level of FoR at each time point, participants were assigned to a subgroup.

To investigate the determinants of functional or dysfunctional FoR at T4, logistic regression modeling, which facilitated the estimation of the sociodemographic and health- and treatment-related characteristics as predictors of FoR with the help of the maximum likelihood method, was applied. The variables were included in a block-wise manner. The first model (M1) contains sociodemographic, health-related, and treatment-related variables. In the second model, the variables fatigue and confidence in treatment were added.

\section{Results}

\section{Descriptive results}

The sample consisted of 184 female breast cancer survivors. $\mathrm{N}=145$ reported no cancer recurrence and $\mathrm{n}=36$ reported to have had a recurrence. The sample characteristics are reported in Table 3. Data on FoR at T1, T3, and $\mathrm{T} 4$ was available for $\mathrm{n}=155$ participants. Of those, $\mathrm{n}=122$ reported no cancer recurrence and $n=32$ reported to have had a recurrence. For $\mathrm{n}=1$, there was no data on recurrence status available.

Figure 2 shows the proportions of functional and dysfunctional FoRs over time. The results revealed a decline in dysfunctional levels of FoR from T1 to T3 and a stable course afterwards.

Regarding individual courses of FoR over time, eight subgroups could be identified (Fig. 3a): (1) $38.1 \%$ of BCSs reported constant functional levels of FoR at all measurement time points; (2) $17.4 \%$ of BCSs showed constant dysfunctional levels of FoR at all measurement time points; (3) $19.4 \%$ of BCSs improved from a dysfunctional to a functional level of FoR from T1 to T3 and remained functional afterwards; (4) 10.3\% of BCSs reported dysfunctional levels of FoR at T1 and T3 and improved to a functional level at $\mathrm{T} 4$; (5) $1.3 \%$ had dysfunctional levels of FoR from T1 to T3 and remained dysfunctional afterwards; (6) 3.2\% showed functional levels of FoR at T1 and T3 and dysfunctional FoR at T4; (7) 7.7\% of BCSs showed dysfunctional levels of FoR at T1 and T4, but reported functional FoR at T3; and (8) $2.6 \%$ of BCSs showed functional levels of FoR at T1 and $\mathrm{T} 4$, but reported dysfunctional FoR at T3.

With regard to BCSs without recurrence (Fig. 3b), (1) $44.3 \%$ of BCSs reported constant functional levels of FoR; (2) $13.1 \%$ of BCSs showed constant dysfunctional levels of FoR; (3) $18 \%$ of BCSs improved from a dysfunctional to a functional level of FoR from T1 to T3 and remained functional afterwards; (4) $9.8 \%$ of BCSs reported dysfunctional levels of FoR at T1 and T3 and improved to a functional level at T4; (5) $1.6 \%$ had dysfunctional levels of FoR from $\mathrm{T} 1$ to $\mathrm{T} 3$ and remained dysfunctional afterwards; (6) $2.5 \%$ showed functional levels of FoR at T1 and T3 and dysfunctional FoR at T4; (7) $9.0 \%$ of BCSs showed dysfunctional levels of FoR at T1 and T4, but reported functional FoR at 
Table 3 Characteristics of study participants $(n=184)$ Abs (\%) Mean $\begin{aligned} & \text { Standard } \\ & \text { deviation }\end{aligned}$ Min-max

\begin{tabular}{|c|c|c|c|c|c|}
\hline \multicolumn{6}{|c|}{ Dependent variable: fear of recurrence (FoR) } \\
\hline \multirow[t]{2}{*}{$\mathrm{T} 1$} & & & 35.10 & 8.61 & $18-60$ \\
\hline & Missing & $13(7.1)$ & & & \\
\hline \multirow[t]{2}{*}{$\mathrm{T} 3$} & & & 31.23 & 8.46 & $16.36-54.55$ \\
\hline & Missing & $20(10.9)$ & & & \\
\hline \multirow[t]{2}{*}{$\mathrm{T} 4$} & & & 29.14 & 9.06 & $12-54$ \\
\hline & Missing & $8(4.3)$ & & & \\
\hline \multicolumn{6}{|c|}{ Independent variables: sociodemographic variables } \\
\hline \multirow[t]{2}{*}{ Age in years $(\mathrm{T} 4)$} & & & 56.93 & 6.82 & $36-79$ \\
\hline & Missing & $15(8.2)$ & & & \\
\hline \multirow[t]{4}{*}{ Marital status (T4) } & Married & $134(72.8)$ & & & \\
\hline & Single & $17(9.2)$ & & & \\
\hline & Divorced/widowed & $33(17.9)$ & & & \\
\hline & Missing & $0(0.0)$ & & & \\
\hline \multirow[t]{2}{*}{ Number of children (T4) } & & & 1.52 & 0.98 & $0-4$ \\
\hline & Missing & $0(0.0)$ & & & \\
\hline \multirow[t]{4}{*}{ Vocational training $(\mathrm{T} 1)$} & Low & $106(57.6)$ & & & \\
\hline & Intermediate & $34(18.5)$ & & & \\
\hline & High & $33(17.9)$ & & & \\
\hline & Missing & $11(6.0)$ & & & \\
\hline \multirow[t]{4}{*}{ Employment status (T4) } & Full time & $51(27.7)$ & & & \\
\hline & $\begin{array}{l}\text { Part time/occupa- } \\
\text { tional rehabilita- } \\
\text { tion }\end{array}$ & $85(46.2)$ & & & \\
\hline & Non-working & $42(22.8)$ & & & \\
\hline & Missing & $6(3.3)$ & & & \\
\hline \multicolumn{6}{|c|}{ Independent variables: health-related variables } \\
\hline \multirow[t]{3}{*}{ UICC TNM stage (T1) } & UICC $0 / 1$ & $79(42.9)$ & & & \\
\hline & UICC $2 / 3 / 4$ & $71(38.6)$ & & & \\
\hline & Missing & $34(18.5)$ & & & \\
\hline \multirow[t]{2}{*}{ Number of comorbidities (T4) } & & & 1.01 & 1.10 & $0-5$ \\
\hline & Missing & $17(9.2)$ & & & \\
\hline \multirow[t]{3}{*}{ Recurrence (T4) } & No & $145(78.8)$ & & & \\
\hline & Yes & $36(19.6)$ & & & \\
\hline & Missing & $3(1.6)$ & & & \\
\hline \multirow[t]{2}{*}{ Fatigue (T4) } & & & 20.75 & 15.62 & $0-59$ \\
\hline & Missing & $1(0.5)$ & & & \\
\hline \multicolumn{6}{|c|}{ Independent variables: treatment-related variables } \\
\hline \multirow[t]{3}{*}{ Chemotherapy (T1, T2, and T3) } & No & $95(51.6)$ & & & \\
\hline & Yes & $80(43.5)$ & & & \\
\hline & Missing & $9(4.9)$ & & & \\
\hline \multirow[t]{3}{*}{ Radiation therapy (T1, T2, and T3) } & No & $113(61.4)$ & & & \\
\hline & Yes & $62(33.7)$ & & & \\
\hline & Missing & $9(4.9)$ & & & \\
\hline \multirow[t]{3}{*}{ Hormonotherapy (T1, T2, and T3) } & No & $54(29.3)$ & & & \\
\hline & Yes & $121(65.8)$ & & & \\
\hline & Missing & $9(4.9)$ & & & \\
\hline \multirow[t]{2}{*}{ Confidence in treatment (T1) } & & & 8.99 & 1.29 & $2-10$ \\
\hline & Missing & $11(6.0)$ & & & \\
\hline
\end{tabular}


Fig. 2 Levels of fear of recurrence at $\mathrm{T} 1, \mathrm{~T} 3$, and $\mathrm{T} 4$. $\mathrm{N}=155$

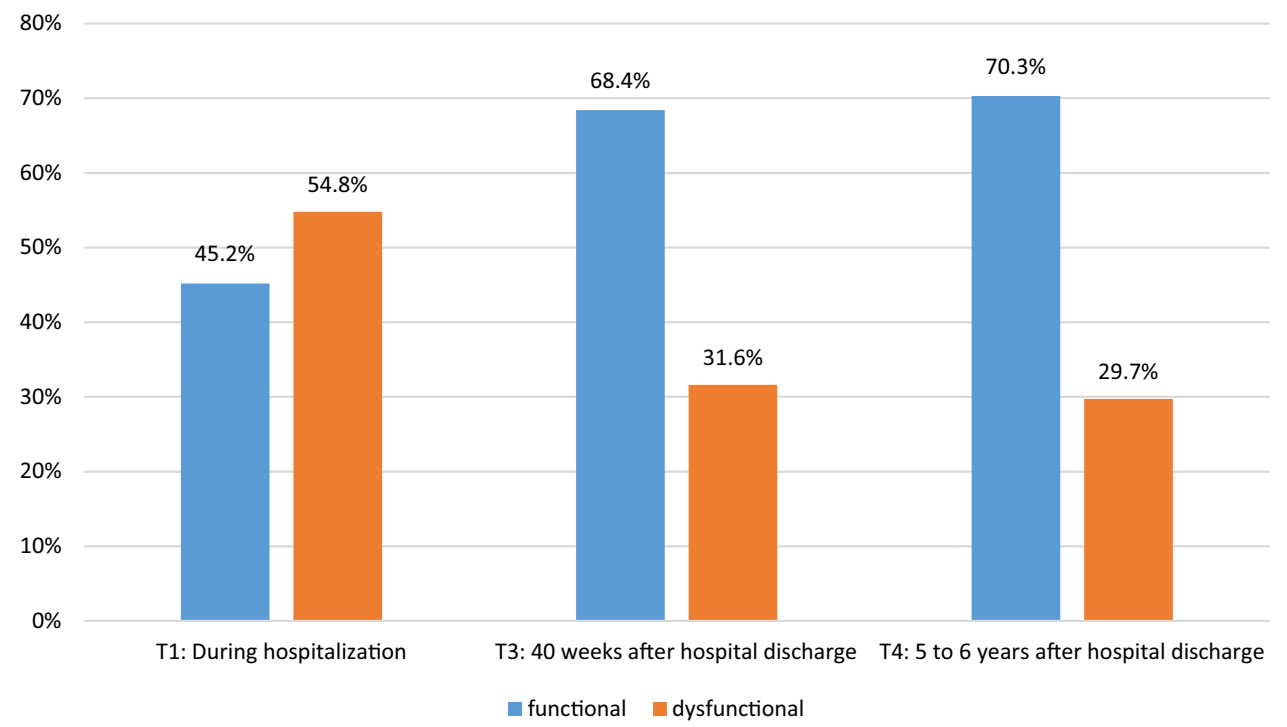

T3; and (8) $1.6 \%$ of BCSs showed functional levels of FoR at $\mathrm{T} 1$ and $\mathrm{T} 4$, but reported dysfunctional FoR at T3.

Regarding BCSs with recurrence (Fig. 3c), seven subgroups could be identified: (1) $15.6 \%$ of BCSs reported constant functional levels of FoR; (2) $34.4 \%$ of BCSs showed constant dysfunctional levels of FoR; (3) $21.9 \%$ of BCSs improved from a dysfunctional to a functional level of FoR from T1 to T3 and remained functional afterwards; (4) $12.5 \%$ of BCSs reported dysfunctional levels of FoR at T1 and T3 and improved to a functional level at T4; (5) $6.3 \%$ of BCSs showed functional levels of FoR at T1 and T3 and dysfunctional FoR at T4; (6) $3.1 \%$ of BCSs showed dysfunctional levels of FoR at T1 and T4, but reported functional FoR at T3; and (7) $6.3 \%$ of BCSs showed functional levels of FoR at T1 and T4, but reported dysfunctional FoR at T3.

\section{Multivariate results}

Chi-square tests of independence were performed to examine the relationship between functional and dysfunctional FoR and time. There was a significant relationship between the levels of FoR and time for T1 and T3 $\left(\chi^{2}(1)=17.11\right.$, $\mathrm{p}=0.000 ; \mathrm{N}=163)$. Dysfunctional levels of FoR were more likely at $\mathrm{T} 1$ than at $\mathrm{T} 3$, indicating a decrease in dysfunction and an increase in functional FoR over time. There was no significant association between functional or dysfunctional levels of FoR and time at T3 and T4 $\left(\chi^{2}(1)=0.14, p=0.71\right.$; $\mathrm{N}=156)$.

To analyze the determinants of dysfunctional FoR 5 to 6 years after initial diagnosis, a logistic regression model was estimated. Table 4 shows the results of the logistic regression for FoR at T4.
Model 1 shows that older adults $(\mathrm{OR}=0.90 ; 95 \%$ $\mathrm{CI}=0.82-1.00)$ and those who reported more comorbidities $(\mathrm{OR}=2.46 ; 95 \% \mathrm{CI}=1.49-4.04)$ were more likely to report dysfunctional FoR at T4. BCSs who were married were less likely to report dysfunctional FoR $(\mathrm{OR}=0.12$; $95 \% \mathrm{CI}=0.03-0.53)$ than those who were divorced or widowed. Being treated with chemotherapy (OR $=10.48 ; 95 \%$ $\mathrm{CI}=2.71-40.53)$ was associated with a higher risk for dysfunctional FoR at T4.

After inclusion of the variables fatigue and confidence in treatment (model 2), the association between age and FoR $(\mathrm{OR}=0.98 ; 95 \% \mathrm{CI}=0.87-1.10)$ and that between comorbidities and FoR $(\mathrm{OR}=1.37 ; 95 \% \mathrm{CI}=0.75-2.52)$ was no longer significant. Like Model 1, Model 2 shows that married BCSs were less likely to report dysfunctional FoR 5 to 6 years after hospital discharge $(\mathrm{OR}=0.14 ; 95 \%$ $\mathrm{CI}=0.02-0.83)$ than those who were divorced or widowed. Being treated with chemotherapy $(\mathrm{OR}=5.53 ; 95 \%$ $\mathrm{CI}=1.22-25.15)$ was associated with a higher risk for dysfunctional FoR at T4. BCSs who reported lower confidence in treatment at $\mathrm{T} 1(\mathrm{OR}=0.63 ; 95 \% \mathrm{CI}=0.41-0.97)$ and higher levels of fatigue $(\mathrm{OR}=1.11 ; 95 \% \mathrm{CI}=1.05-1.12)$ were more likely to show dysfunctional levels of FoR at T4.

\section{Discussion}

Regarding the prevalence of FoR among BCSs, the results show that 5 to 6 years after hospitalization, most BCSs $(70 \%)$ experienced functional levels of FoR. However, almost onethird of the BCSs reported dysfunctional levels of FoR. This number is higher compared to that reported in other studies $[9,10]$. These differences may be explained by the younger age and employment status of the participants in the study 
Fig. 3 (a) Individual courses of fear of cancer recurrence from T1 to T4 $(\mathrm{n}=155)$; (b) individual courses of fear of cancer recurrence from $\mathrm{T} 1$ to T4 of BCSs without recurrence $(\mathrm{n}=122)$; (c) individual courses of fear of cancer recurrence from $\mathrm{T} 1$ to $\mathrm{T} 4$ of BCSs with recurrence $(n=32)$

\section{(a)}

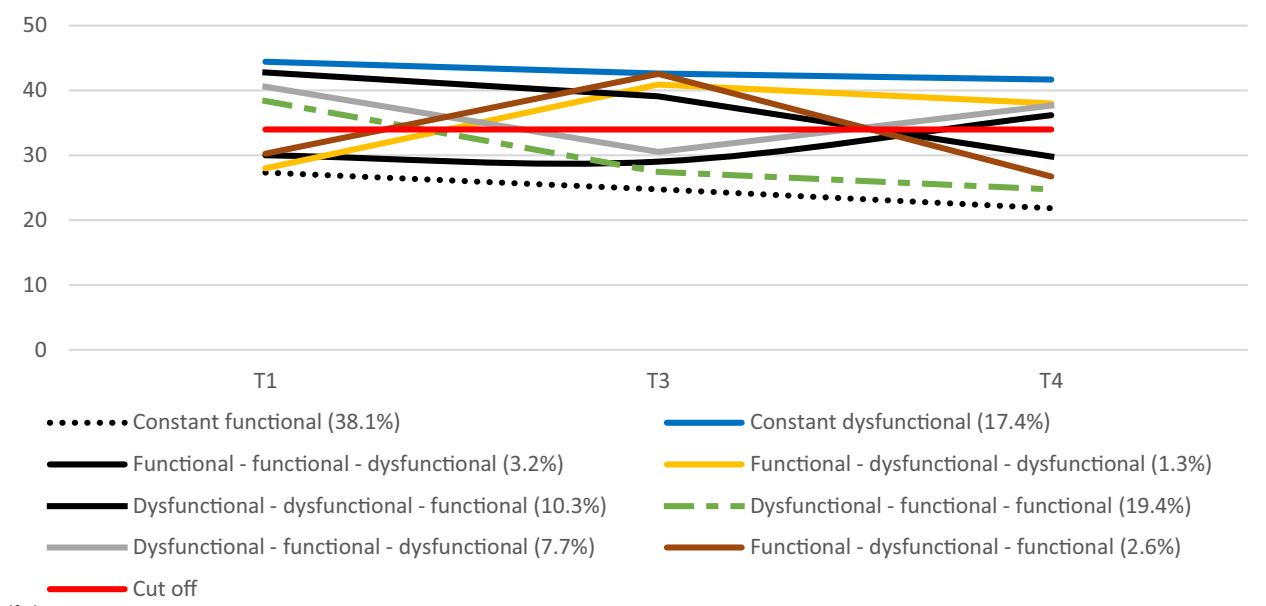

(b)

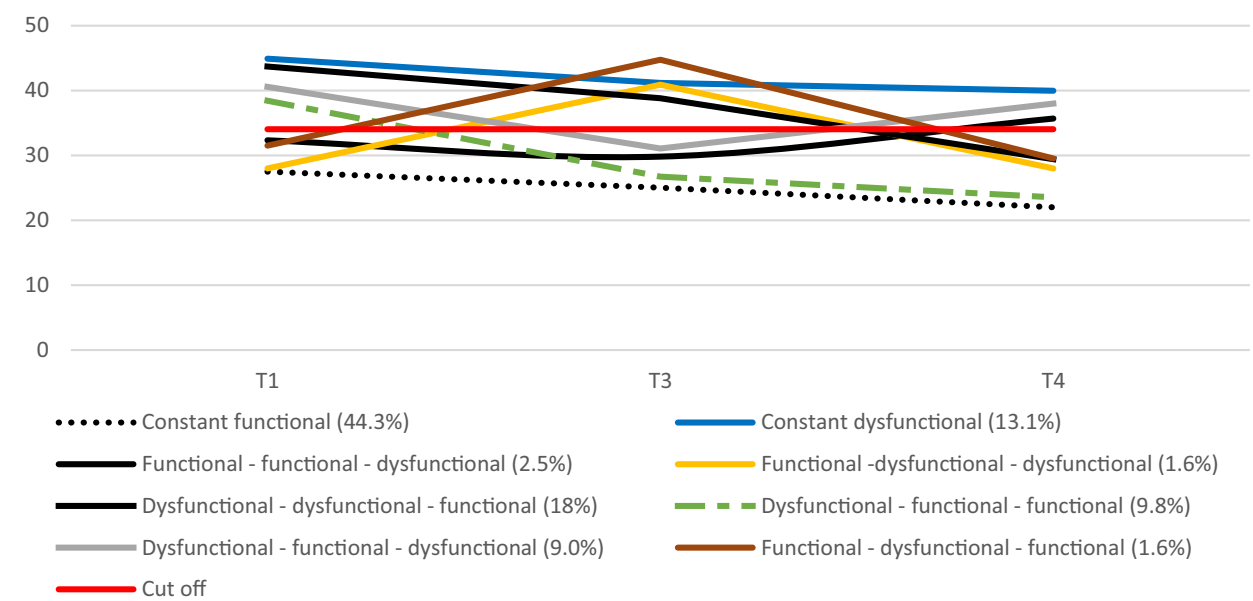

(c)

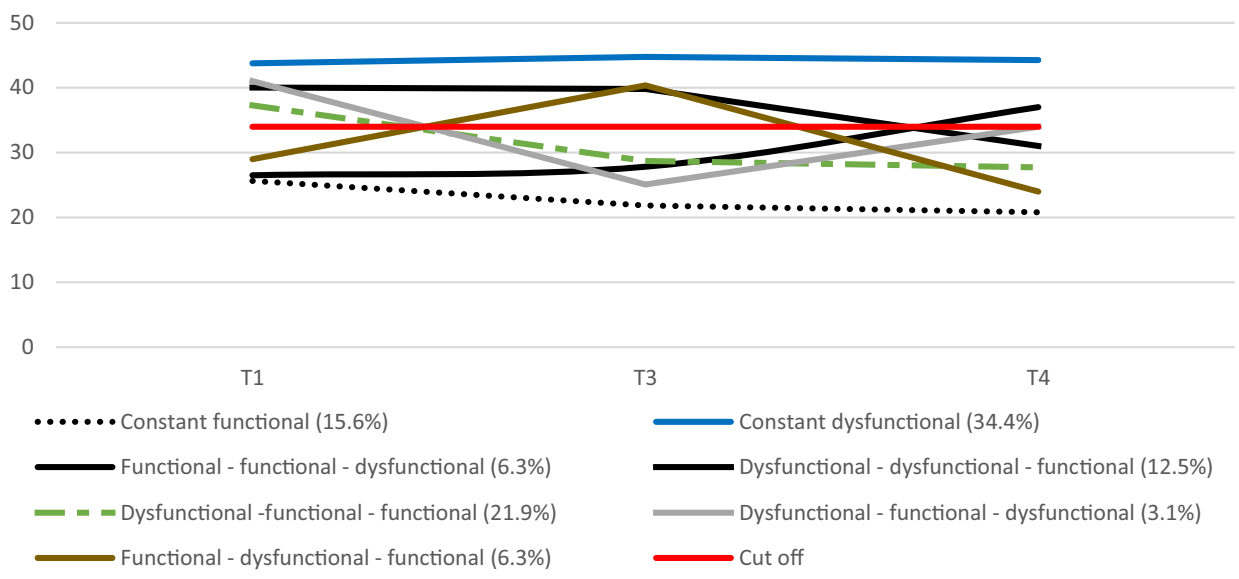

sample. There is strong evidence that younger age is associated with higher FoR [5, 23]. With regard to employment status, it must be noted that the FoP-Q-SF includes two items that evaluate occupational worries, leading to a higher FoR score if working life is still an issue.
Regarding the average course of FoR over time, the results show a decrease in dysfunctional and an increase in functional levels of FoR during the first 40 weeks after hospital discharge and a stable course 5 to 6 years after hospital discharge. These results are comparable to those of 
Table 4 Logistic regression model with fear of recurrence as the dependent variable $(n=140)$

\begin{tabular}{|c|c|c|c|c|c|}
\hline \multirow[b]{2}{*}{ Variables } & \multirow[b]{2}{*}{ Response trait } & \multicolumn{2}{|c|}{ Model 1} & \multicolumn{2}{|c|}{ Model 2} \\
\hline & & OR & $95 \% \mathrm{CI}$ & OR & $95 \% \mathrm{CI}$ \\
\hline Age in years & Metric & $0.90 *$ & $0.82-1.00$ & 0.98 & $0.87-1.10$ \\
\hline \multirow[t]{3}{*}{ Marital status } & Married & $0.12 * *$ & $0.03-0.53$ & $0.14^{*}$ & $0.02-0.83$ \\
\hline & Single & 0.17 & $0.20-1.43$ & 0.57 & $0.04-9.04$ \\
\hline & Divorced/widowed & 1.0 & & 1.0 & \\
\hline Number of children & Metric & 1.17 & $0.70-1.96$ & 1.01 & $0.56-1.81$ \\
\hline \multirow[t]{3}{*}{ Vocational training } & Low & 2.02 & $0.59-6.99$ & 1.77 & $0.39-8.08$ \\
\hline & Intermediate & 0.76 & $0.16-3.72$ & 0.59 & $0.90-3.86$ \\
\hline & High & 1.0 & & 1.0 & \\
\hline \multirow[t]{3}{*}{ Employment status } & Full time & 0.78 & $0.16-3.99$ & 2.06 & $0.24-17.43$ \\
\hline & $\begin{array}{l}\text { Part time/occupational } \\
\text { rehabilitation }\end{array}$ & 0.85 & $0.21-3.56$ & 2.26 & $0.40-12.69$ \\
\hline & Non-working & 1.0 & & 1.0 & \\
\hline \multirow[t]{2}{*}{ UICC TNM stage } & Stage $0 / \mathrm{I}$ & 0.75 & $0.23-2.38$ & 0.76 & $0.19-3.12$ \\
\hline & Stage II/III/IV & 1.0 & & 1.0 & \\
\hline Number of comorbidities & Metric & $2.46^{* *}$ & $1.49-4.04$ & 1.37 & $0.75-2.52$ \\
\hline \multirow[t]{2}{*}{ Recurrence } & No & 2.23 & $0.71-6.94$ & 1.50 & $0.38-5.98$ \\
\hline & Yes & 1.0 & & & \\
\hline \multirow[t]{2}{*}{ Chemotherapy } & Yes & $10.48^{*}$ & $2.71-40.53$ & $5.53 *$ & $1.22-25.15$ \\
\hline & No & 1.0 & & 1.0 & \\
\hline \multirow[t]{2}{*}{ Radiation therapy } & Yes & 2.63 & $0.81-8.59$ & 2.99 & $0.74-12.12$ \\
\hline & No & 1.0 & & 1.0 & \\
\hline \multirow[t]{2}{*}{ Hormonotherapy } & Yes & 2.95 & $0.92-9.46$ & 2.55 & $0.67-9.72$ \\
\hline & No & 1.0 & & 1.0 & \\
\hline Fatigue & Metric & & & $1.11 * *$ & $1.05-1.17$ \\
\hline Confidence in treatment & Metric & & & $0.63^{*}$ & $0.41-0.97$ \\
\hline Nagelkerkes- $\mathrm{R}^{2}$ & & 0.461 & & 0.632 & \\
\hline
\end{tabular}

$* \mathrm{p}<0.05 ; * * \mathrm{p}<0.01$. Functional $\mathrm{FoR}=0$, dysfunctional $\mathrm{FoR}=1$ other studies that show a decrease in FoR during the first year after diagnosis but no long-term effect of time after diagnosis [9, 24-26].

Considering the overall sample, most BCSs showed constant functional levels of FoR (38.1\%), followed by BCSs who improved from a dysfunctional to a functional level over time (29.7\%) and BCSs who reported constant dysfunctional FoR (17.4\%). Only a small number of BCSs showed a functional level of FoR at T1 and a dysfunctional level of FoR at T4 (4.5\%). As the majority of BCSs in the present study showed steady FoR in terms of functional or dysfunctional levels, our findings partly support those of studies that found FoR in cancer survivors to be stable over time $[4,5]$. On the other hand, in almost $45 \%$ of the participants, the intensity of FoR changed over the course of 5 to 6 years, indicating that time has the potential to affect FoR.

When comparing the individual courses of FoR of BCSs with and without recurrence, it appears that BCSs with recurrence descriptively show more often constant dysfunctional FoR (34.4\%) and less often constant functional levels of FoR (15.6\%) over the course of 5-6 years after diagnosis than BCSs without recurrence. These results suggest a positive association between having had a recurrence and dysfunctional FoR and are in accordance with previous research [9]. Furthermore, the results suggest that BCSs with recurrence show more dysfunctional FoR right from the start, even before having the actual recurrence.

The results of the logistic regression revealed a significant association between the marital status and the intensity of FoR in long-term BCSs. Women who were married were less likely to report dysfunctional FoR 5 to 6 years after diagnosis than women who were divorced or widowed. However, the effect was small $(\mathrm{OR}=0.14)$. This association could be explained in terms of social support, which is probably more available for married than for divorced or widowed BCSs. Social support acts as a protective factor to lower the impact of stressors [27] and is negatively associated with higher FoR in long-term cancer survivors [28].

Furthermore, BCSs who were suffering from higher levels of fatigue were more likely to show dysfunctional FoR 5 to 6 years after diagnosis than BCSs who experience low levels of fatigue. These results are in accordance with 
previous research, which found strong evidence for the association between fatigue and other physical symptoms related to higher FoR [5]. This relationship might be explained by the ability of bodily sensations to trigger thoughts about cancer recurrence and the corresponding emotions and the fact that hypervigilance to bodily symptoms is a key characteristic of dysfunctional FoR [8].

BCSs who were treated with chemotherapy were at a higher risk for dysfunctional FoR at T4. These results are comparable to those of other studies [10, 29]. Adjuvant therapy is performed in order to reduce the risk of cancer recurrence and to draw the patients' attention to this risk, leading to higher levels of FoR. Another explanation for this association might be the long-term side effects of the therapy, which still cause physical symptoms years after treatment. Furthermore, treatment with chemotherapy could be an indicator of the severity of the cancer, leading to higher levels of FoR. However, cancer staging was not a significant predictor of FoR in the present study. In addition, chemotherapy often is recommended to younger cancer patients, who tend to show higher levels of FoR [5, 23].

Moreover, BCSs who reported lower confidence in treatment during hospitalization were more likely to show dysfunctional levels of FoR at T4 compared to BCSs who were more optimistic about their therapy. These results confirm those of previous studies that identified pessimism as a risk factor for cancer-related health concerns, anxiety, and depression in cancer survivors [30, 31].

The first model revealed significant associations between age and FoR at T4 as well as comorbidities and FoR at T4. After including the variables fatigue and confidence in treatment, the associations were no longer significant. This effect might be explained by the correlations between the variables, leading to the disappearance of the associations in the second model.

\section{Study limitations}

There are some study limitations which should be considered when interpreting the presented results.

The B-CARE study is an observational, and not an experimental, study. Therefore, only associations, but not causality, can be drawn from the results. The present study used a longitudinal study design with data collection at several measurement time points over a time span of 5 to 6 years. It is possible that study participants differ from non-participants in terms of health condition and emotional strain, which could have affected their motivation or ability to participate in the study. This bias could have led to an underestimation of the FoR of the BCSs. However, responder and non-responder at T4 did not differ significantly regarding FoR, medical, psychosocial, and sociodemographic characteristics.
Moreover, the use of a written survey could have resulted in the exclusion of patients who do not have sufficient reading, writing, or language skills. In terms of generalizability, it should be noted that only BCSs who worked prior to their diagnosis were considered in the present study. Therefore, a bias toward a younger and more educated sample is possible.

By interpreting the individual courses of FoR, it is important to consider that the courses were illustrated descriptively and that some of the subgroups have low sample sizes.

\section{Clinical implications}

The presented findings emphasize the relevance of FoR in BCSs and indicate that a significant number of BCSs suffer from dysfunctional fear and worries even years after diagnosis. As different courses of FoR have been illustrated, continuous screening for FoR over the course of the disease and survivorship is required. Therefore, health personnel in inpatient and outpatient settings should be aware of FoR and its characteristics, which indicate dysfunctional levels of FoR (e.g., hypervigilance to bodily symptoms). The presented findings on the determinants of dysfunctional FoR in long-term BCSs could be helpful in identifying high-risk groups, such as those who are divorced or widowed, those who have been treated using chemotherapy, those who report low confidence in treatment right from the start, and those who report high levels of fatigue as a long-term consequence of the cancer. In addition, therapeutic interventions could be derived from the reported risk factors, for example, activation of social networks or cognitive restructuring regarding the meaning of bodily symptoms. At the same time, it should be acknowledged that there are many proven interventions for FoR (e.g., ConquerFear [32]). The study results reveal that a substantial number of BCSs have constant dysfunctional levels of FoR over a period of 5 to 6 years, indicating that for many BCSs, time, per se, does not have a curative effect. Therefore, more support options accessible for both cancer patients and long-term cancer survivors in the health care system are required.

\section{Conclusion}

Overall, the findings from this study suggest that FoR is a significant issue among long-term BCSs. Almost onethird of the BCSs reported dysfunctional levels of FoR 5 to 6 years after diagnosis, indicating the potential of FoR to be a serious and persistent psychological strain following cancer. The findings support the need for increased awareness of the presence of FoR during and years after treatment and the need for support programs. Attention should be given to those who are divorced or widowed, who have undergone chemotherapy, who show low confidence in treatment, and 
who report high levels of fatigue. To gain a deeper understanding of FoR in cancer survivors, further studies involving both quantitative and qualitative data are needed.

Author contribution Nicole Ernstmann, Christoph Kowalski, and Holger Pfaff designed and supervised the PIAT study. Anna Enders collected PIAT data. Paula Heidkamp and Kati Hiltrop collected B-CARE data and matched B-CARE to PIAT data. Paula Heidkamp performed data analysis. Paula Heidkamp wrote the first draft of the manuscript. Clara Breidenbach, Kati Hiltrop, Nicole Ernstmann, Christoph Kowalski, Birgitta Weltermann, Franziska Geiser, Anna Enders, and Holger Pfaff discussed the results and commented on the manuscript.

Funding Open Access funding enabled and organized by Projekt DEAL. PIAT was funded by the German Federal Ministry of Health (grant number NKP-332-052). B-CARE was funded by the German Statutory Pension Insurance (grant number 8011-106-31/31.128).

Data availability Research data are not shared.

Code availability Not applicable.

\section{Declarations}

Ethics approval The approval of the ethics committees of the Medical Faculties of the University of Bonn (reference number: 316/18) and University of Cologne (reference number: 12-171) was obtained.

Consent to participate Written informed consent was obtained from all individual participants included in the study.

Consent for publication All participants gave written informed consent for data analysis and publication.

Conflict of interest Clara Breidenbach and Christoph Kowalski are employees of the German Cancer Society.

Open Access This article is licensed under a Creative Commons Attribution 4.0 International License, which permits use, sharing, adaptation, distribution and reproduction in any medium or format, as long as you give appropriate credit to the original author(s) and the source, provide a link to the Creative Commons licence, and indicate if changes were made. The images or other third party material in this article are included in the article's Creative Commons licence, unless indicated otherwise in a credit line to the material. If material is not included in the article's Creative Commons licence and your intended use is not permitted by statutory regulation or exceeds the permitted use, you will need to obtain permission directly from the copyright holder. To view a copy of this licence, visit http://creativecommons.org/licenses/by/4.0/.

\section{References}

1. Götze H, Taubenheim S, Dietz A, Lordick F, Mehnert A (2018) Comorbid conditions and health-related quality of life in longterm cancer survivors-associations with demographic and medical characteristics. Journal of cancer survivorship research and practice 12(5):712-720. https://doi.org/10.1007/s11764-018-0708-6

2. van Leeuwen M, Husson O, Alberti P, Arraras JI, Chinot OL, Costantini A et al (2018) Understanding the quality of life (QOL) issues in survivors of cancer: towards the development of an EORTC QOL cancer survivorship questionnaire. Health Qual Life Outcomes 16(1):114. https://doi.org/10.1186/s12955-018-0920-0

3. Herschbach P, Keller M, Knight L, Brandl T, Huber B, Henrich G et al (2004) Psychological problems of cancer patients: a cancer distress screening with a cancer-specific questionnaire. Br J Cancer 91(3):504. https://doi.org/10.1038/sj.bjc.6601986

4. Koch L, Jansen L, Brenner H, Arndt V (2013) Fear of recurrence and disease progression in long-term ( $\geq 5$ years) cancer survivors-a systematic review of quantitative studies. Psychooncology 22(1):1-11. https://doi.org/10.1002/pon.3022

5. Simard S, Thewes B, Humphris G, Dixon M, Hayden C, Mireskandari $S$ et al (2013) Fear of cancer recurrence in adult cancer survivors: a systematic review of quantitative studies. J Cancer Surviv 7(3):300-322. https://doi.org/10.1007/s11764-013-0272-z

6. Lebel S, Ozakinci G, Humphris G, Mutsaers B, Thewes B, Prins J et al (2016) From normal response to clinical problem: definition and clinical features of fear of cancer recurrence. Support Care Cancer 24(8):3265-3268. https://doi.org/10.1007/ s00520-016-3272-5

7. Dinkel A, Herschbach P (2018) Fear of progression in cancer patients and survivors. Recent results in cancer research. Fortschritte der Krebsforschung. Progres dans les recherches sur le cancer 210:13-33. https://doi.org/10.1007/978-3-319-643106_2

8. Mutsaers B, Butow P, Dinkel A, Humphris G, Maheu C, Ozakinci $G$ et al (2020) Identifying the key characteristics of clinical fear of cancer recurrence: an international Delphi study. Psychooncology 29(2):430-436. https://doi.org/10.1002/pon.5283

9. Koch L, Bertram H, Eberle A, Holleczek B, Schmid-Höpfner S, Waldmann A et al (2014) Fear of recurrence in long-term breast cancer survivors-still an issue. Results on prevalence, determinants, and the association with quality of life and depression from the cancer survivorship-a multi-regional population-based study. Psycho-Oncology 23(5):547-54. https://doi.org/10.1002/pon.3452

10. Götze H, Taubenheim S, Dietz A, Lordick F, Mehnert-Theuerkauf A (2019) Fear of cancer recurrence across the survivorship trajectory: results from a survey of adult long-term cancer survivors. Psychooncology 28(10):2033-2041. https://doi.org/10.1002/pon. 5188

11. Simard S, Savard J (2015) Screening and comorbidity of clinical levels of fear of cancer recurrence. J Cancer Surviv 9(3):481-491. https://doi.org/10.1007/s11764-015-0424-4

12. Ng DWL, Foo C-C, Ng SSM, Kwong A, Suen D, Chan M et al (2020) The role of metacognition and its indirect effect through cognitive attentional syndrome on fear of cancer recurrence trajectories: a longitudinal study. Psychooncology 29(2):271-279. https://doi.org/10.1002/pon.5234

13. Manne SL, Myers-Virtue S, Kissane D, Ozga ML, Kashy DA, Rubin SC et al (2017) Group-based trajectory modeling of fear of disease recurrence among women recently diagnosed with gynecological cancers. Psychooncology 26(11):1799-1809. https://doi.org/10.1002/pon.4223

14. Schmidt A, Kowalski C, Pfaff H, Wesselmann S, Wirtz M, Ernstmann N (2015) The influence of health literacy on information needs among women newly diagnosed with breast cancer, with special reference to employment status. J Health Commun 20(10):1177-1184. https://doi.org/10.1080/10810730.2015.10186 26

15. Halbach SM, Ernstmann N, Kowalski C, Pfaff H, Pförtner T-K, Wesselmann $S$ et al (2016) Unmet information needs and limited health literacy in newly diagnosed breast cancer patients over the course of cancer treatment. Patient Educ Couns 99(9):1511-1518. https://doi.org/10.1016/j.pec.2016.06.028

16. Hiltrop K, Heidkamp P, Kowalski C, Ernstmann N (2019) Breast cancer patients' return to work (B-CARE): protocol of a 
longitudinal mixed-methods study aiming to explore medical and occupational rehabilitation of patients with breast cancer in Germany. BMJ Open 9(12):e033533. https://doi.org/10.1136/bmjop en-2019-033533

17. Mehnert A, Herschbach P, Berg P, Henrich G, Koch U (2006) Progredienzangst bei Brustkrebspatientinnen-Validierung der Kurzform des Progredienzangstfragebogens PA-F-KF. Zeitschrift fur Psychosomatische Medizin und Psychotherapie 52(3):274-88. https://doi.org/10.13109/zptm.2006.52.3.274

18. Herschbach P, Berg P, Dankert A, Duran G, Engst-Hastreiter U, Waadt $S$ et al (2005) Fear of progression in chronic diseases. J Psychosom Res 58(6):505-511. https://doi.org/10.1016/j.jpsyc hores.2005.02.007

19. Mehnert A, Berg P, Henrich G, Herschbach P (2009) Fear of cancer progression and cancer-related intrusive cognitions in breast cancer survivors. Psychooncology 18(12):1273-1280. https://doi. org/10.1002/pon.1481

20. Herschbach P, Berg P, Waadt S, Duran G, Engst-Hastreiter U, Henrich $G$ et al (2010) Group psychotherapy of dysfunctional fear of progression in patients with chronic arthritis or cancer. Psychother Psychosom 79(1):31-38. https://doi.org/10.1159/00025 4903

21. Sobin LH, Gospodarowicz MK, Wittekind C (2011) TNM Classification of Malignant Tumours, 7th edn. Wiley, Somerset

22. Glaus A, Müller S (2001) Messung der Müdigkeit bei Krebskranken im Deutschen Sprachraum: Die Entwicklung des Fatigue Assessment Questionnaires. Pflege 14(3):161-170. https://doi.org/ 10.1024/1012-5302.14.3.161

23. Thewes B, Butow P, Bell ML, Beith J, Stuart-Harris R, Grossi $M$ et al (2012) Fear of cancer recurrence in young women with a history of early-stage breast cancer: a cross-sectional study of prevalence and association with health behaviours. Support Care Cancer 20(11):2651-2659. https://doi.org/10.1007/ s00520-011-1371-x

24. Mehnert A, Koch U, Sundermann C, Dinkel A (2013) Predictors of fear of recurrence in patients one year after cancer rehabilitation: a prospective study. Acta Oncol 52(6):1102-1109. https:// doi.org/10.3109/0284186X.2013.765063
25. Melchior H, Büscher C, Thorenz A, Grochocka A, Koch U, Watzke B (2013) Self-efficacy and fear of cancer progression during the year following diagnosis of breast cancer. Psychooncology 22(1):39-45. https://doi.org/10.1002/pon.2054

26. Lebel S, Rosberger Z, Edgar L, Devins GM (2007) Comparison of four common stressors across the breast cancer trajectory. J Psychosom Res 63(3):225-232. https://doi.org/10.1016/j.jpsyc hores.2007.02.002

27. Lazarus RS, Folkman S 1984 Stress, appraisal, and coping

28. Koch-Gallenkamp L, Bertram H, Eberle A, Holleczek B, SchmidHöpfner S, Waldmann A et al (2016) Fear of recurrence in longterm cancer survivors-do cancer type, sex, time since diagnosis, and social support matter? Health Psychol 35(12):1329-1333. https://doi.org/10.1037/hea0000374

29. Simard S, Savard J (2009) Fear of cancer recurrence inventory: development and initial validation of a multidimensional measure of fear of cancer recurrence. Support Care Cancer 17(3):241. https://doi.org/10.1007/s00520-008-0444-y

30. Faye-Schjøll HH, Schou-Bredal I (2019) Pessimism predicts anxiety and depression in breast cancer survivors: a 5-year follow-up study. Psychooncology 28(6):1314-1320. https://doi.org/10.1002/ pon.5084

31. Deimling GT, Bowman KF, Sterns S, Wagner LJ, Kahana B (2006) Cancer-related health worries and psychological distress among older adult, long-term cancer survivors. Psychooncology 15(4):306-320. https://doi.org/10.1002/pon.955

32. Butow PN, Turner J, Gilchrist J, Sharpe L, Smith AB, Fardell JE et al (2017) Randomized trial of ConquerFear: a novel, theoretically based psychosocial intervention for fear of cancer recurrence. JCO 35(36):4066-4077. https://doi.org/10.1200/JCO.2017. 73.1257

Publisher's note Springer Nature remains neutral with regard to jurisdictional claims in published maps and institutional affiliations. 